\title{
"Cifro en sangre poema y poesía": el secreto abierto y la tradición homoerótica latinoamericana
}

\author{
"I Code in Blood Poem and Poetry": The Open Secret \\ and the Latin American Homoerotic Tradition \\ "Cifro em sangue poema e poesia": o segredo aberto \\ e a tradição homoerótica latino-americana
}

\section{Daniel Balderston}

UNIVERSITY OF PITTSBURGH

Profesor del Departamento de Literaturas Hispánicas en la Universidad de

Pittsburgh. PhD en Literatura Comparada, Princeton University. Director del Centro Borges y editor de la revista Variaciones Borges en la misma universidad. Es autor de El deseo, enorme cicatriz luminosa. Ensayos sobre homosexualidades latinoamericanas (Beatriz Viterbo Editora, 2004), Borges, realidades y simulacros (Biblios, 2000), Out of Context: Historical Reference and the Representation of Reality in Borges (Duke University Press, 1993), El precursor velado: R. L. Stevenson en la obra de Borges (Sudamericana, 1985). Correo electrónico: dbalder@pitt.edu 


\section{Resumen}

A partir de un poema de Carlos Pellicer que incluye un mensaje cifrado de amor, se examina en este trabajo una serie de vínculos poéticos y amorosos en el grupo mexicano de los Contemporáneos (incluyendo algunas figuras aledañas, como el hondureño Rafael Heliodoro Valle). El artículo se centra en la comunicación de "secretos" del amor homosexual, que al convertirse en motivos poéticos pasan de lo privado a lo público.

\section{Palabras clave: poesía} homoerótica, Contemporáneos, secreto, Octavio Paz, Carlos Pellicer, Salvador Novo, Xavier Villaurrutia, Rafael Heliodoro Valle, Elías Nandino.

Palabras descriptor: $\mathrm{Paz}$, Octavio, 1914-1998, Pellicer Cámara, Carlos, 1897-1977, Novo, Salvador, 1904-1974, Villaurrutia, Xavier, 1903-1950, Nandino Vallarta, Elías, 19001993, poetas mexicanos, Valle, Rafael Heliodoro, 1891-1959, poetas hondureños, poesía erótica, literatura moderna.

\section{Abstract}

From a poem by Carlos Pellicer that includes an encrypted love message, it is examined in this paper a series of poetic and romantic ties to the Mexican group Los Contemporáneos (including some surrounding figures like the Honduran Rafael Heliodorus Valle). The article focuses on the communication of "secrets" of homosexual love, that once become poetic motifs, move from private to public.

Keywords: homoerotic poetry,

Contemporáneos, secret, Octavio Paz, Carlos Pellicer, Salvador Novo, Xavier Villaurrutia, Rafael Heliodorus Valle, Elias Nandino. Keywords plus: Paz, Octavio, 1914-1998, Pellicer Cámara, Carlos, 1897-1977, Novo, Salvador, 1904-1974, Villaurrutia, Xavier, 1903-1950, Nandino Vallarta, Elías, 19001993, poets-mexican, Valle, Rafael Heliodoro, 1891-1959, poets-Honduras, erotic poetry, modern literature.

\section{Resumo}

A partir de um poema de Carlos Pellicer incluindo mensagem cifrada de amor, examina-se neste trabalho a série de vínculos poéticos e amorosos no grupo mexicano dos Contemporâneos (incluindo algumas figuras circundantes, como o hondurenho Rafael Heliodoro Valle). $\mathrm{O}$ artigo centra-se na comunicação de "segredos" do amor homossexual, que se tornando motivos poéticos passam do privado ao público.

Palavras-chave: poesia homoerótica, Contemporâneos, segredo, Octavio Paz, Carlos Pellicer, Salvador Novo, Xavier Villaurrutia, Rafael Heliodoro Valle, Elías Nandino. Palavras-chave descritores: Paz, Octavio, 1914-1998, Pellicer Cámara, Carlos, 1897-1977, Novo, Salvador, 1904-1974, Villaurrutia, Xavier, 1903-1950, Nandino Vallarta, Elias, 19001993, poetas mexicanos, Valle, Rafael Heliodoro 1891-1959, poetas de Honduras, poesia erótica, literatura moderna.

RECIBIDO: 14 DE JULIO DE 2013. EVALUAdO: 5 DE AGOSTO DE 2013. ACEPTADO: 5 DE AGOSTO DE 2013.

\section{Cómo citar este artículo:}

Balderston, Daniel. "'Cifro en sangre poema y poesía': el secreto abierto y la tradición homoerótica latinoamericana". Cuadernos de Literatura 18.35 (2014): 198-210. 
UNA S O R P ESA, UN secreto: un poema de amor que Carlos Pellicer le escribió a un joven amante el 31 de julio de 1931:

Salir a verte sin que nadie sepa que tu belleza sólo me redime.

Tu alegría es minero de palabras que me ordena las pula y las apile.

Toda tu lozanía

es el regalo de las frutas vivas

que en cerámica fuerza da tu vida.

Cuanto tu mano al saludar me toca, en la frugalidad dese momento tengo todo el placer de tu persona.

En tu risa la piña paladea un aire naranjal y en dos aromas tu adolescencia tropical vocea.

Eres el agua nueva que se baña en la muelle espiral de mi remanso que saltea la sombra de las cañas.

Caña y piña en un orbe anaranjado crucen el nombre junto al agua en vidrio que en la mesa del sueño he dejado.

Toda la lozanía que en octavos de tono - paz intensacifro en sangre poema y poesía. (Poesía completa 2: 366-367)

El secreto está revelado a medias al final del poema (que no tiene ni título ni dedicatoria). Allí está cifrado el nombre del futuro Premio Nobel de Literatura, Octavio Paz Lozano. El poema juega con la retórica del secreto abierto: el joven amado es alegre, lo ilumina el sol tropical, llena de placer al poeta. (Todo esto de "llenar de placer" no es metáfora, por la referencia a la "cerámica fuerza" del 
amante adolescente). A la vez, todo esto pasa a la vista de todos pero "sin que nadie sepa", y la manera en que Pellicer oculta el nombre del amado en el poema (insistiendo apenas en el apellido materno, que aparece dos veces como "Toda la lozanía") hace hincapié en el secreto compartido ${ }^{1}$.

Debo el conocimiento de la intriga que está detrás de este poema a Juan Pellicer, profesor de literatura hispanoamericana en la Universidad de Oslo y sobrino nieto del poeta, y (para más detalles) a Carlos Monsiváis. Por lo tanto, el reconocimiento del poema como clave de una relación homosexual depende no solo de la relación intertextual sino del arte verbal del chisme, brillantemente analizado por Edgardo Cozarinsky en Museo del chisme ${ }^{2}$. El poema de Pellicer está incluido en una antología de poesía gay en la red (que tiene el sugerente nombre "No eres el ÚNICO adolescente gay"3), pero que yo sepa nadie ha publicado nunca nada que identifique el objeto amado con Paz, detalle que serviría para aclarar algunas de sus meditaciones posteriores sobre el erotismo, la masculinidad y la femineidad, y la homosexualidad ${ }^{4}$. Es decir, el poema ha circulado por casi ochenta años "sin que nadie sepa", o por lo menos sin que nadie lo publique. Como el anillo que le regaló Teresa de la Parra a Lydia Cabrera en su lecho de muerte, bisagra de un artículo famoso de Sylvia Molloy ${ }^{5}$, el dato sirve para hacer público algo que estaba a la vista, pero de modo oculto, durante todos estos años.

Es un caso extremo pero forma parte de un conjunto amplio de poemas en los que un poeta le dedica un texto amoroso a otro, formando redes de secretos abiertos y posibilitando chismes. De este modo, son poemas en los que la retórica del silencio, como la ha denominado Lisa Block de Behar en otro contexto, intriga y seduce al lector, ávido de saber más sobre las circunstancias que no se cuentan en los poemas. Estos intercambios son especialmente notables entre los poetas del "grupo

1 Un poema escrito ocho años más tarde, "Ocio", comienza con el verso "Paz de la biblioteca, paz de sabiduría" (2: 378-379). Desconozco si la relación continuó luego del matrimonio de Paz y Elena Garro en 1937, y ya no está Carlos Monsiváis para preguntarle.

2 Cozarinsky parte de una consideración del chisme en Proust, pero su "museo" abarca todo tipo de chismes escritos y orales.

3 Otro curioso ejemplo de la circulación de la poesía de los Contemporáneos es el texto de Noé Carrillo Martínez, "Trizar la distancia, romper el aire: postales a Xavier Villaurrutia", en el libro compilado por Roxana Elvridge-Thomas, en el que el joven poeta mexicano le confiesa a Villaurrutia sus aventuras amorosas, décadas después de la muerte de X. V. Otro texto del mismo libro que traza una línea semejante es el de Cuitláhuac Quiroga, "Avistamientos a Xavier Villaurrutia". Es decir, los Contemporáneos se homenajean como pioneros de la expresión homoerótica mexicana, aun entre los jóvenes poetas de la década actual.

4 Pienso, claro, en el ensayo sobre Villaurrutia, las meditaciones sobre género y sexualidad en $E l$ laberinto de la soledad, y el libro sobre el erotismo, La llama doble.

5 El ensayo, publicado originalmente en 1995, ha sido recogido en Poses de fin de siglo. 
sin grupo" de los Contemporáneos (Novo, Villaurrutia, Cuesta, Torres Bodet) y sus aledaños (Porfirio Barba Jacob de Colombia ${ }^{6}$, Rafael Heliodoro Valle de Honduras, César Moro del Perú y Juan Cotto de El Salvador) ${ }^{7}$. Lo que propongo hacer aquí, e iré mucho más allá de la tímida exploración del tema en The Contemporáneos Group de Salvador Oropeza, es dilucidar algunas de esas relaciones, y mostrar cómo la comunicación del secreto (tema de un elocuente ensayo de José Quiroga sobre la correspondencia entre Villaurrutia y Novo) es un gesto fundador de una tradición ${ }^{8}$.

La retórica del secreto es común entre los Contemporáneos. Víctor Manuel Mendiola afirma que "el secreto que guardaba la poesía de Villaurrutia y los Contemporáneos, de manera contradictoria, no ha sido revelado. Se mantiene intacto" (80). Cuenta Elías Nandino:

En los primeros tiempos de nuestra amistad, Xavier, Salvador, Roberto, Jorge, Gilberto y yo formamos un grupo a partir de nuestros intereses literarios y de nuestras complicidades existenciales, grupo a través del cual compartíamos tremendas conversaciones sexuales o sentimentales, pero también intelectuales. (64)

El "también intelectuales" agrega una nota extraña, de excesiva insistencia, a los recuerdos de esas "complicidades". El más famoso de los poemas homoeróticos del grupo, el "Nocturno de los ángeles" de Xavier Villaurrutia, comienza así:

Se diría que las calles fluyen dulcemente en la noche.

Las luces no son tan vivas que logren desvelar el secreto, el secreto que los hombres que van y vienen conocen, porque todos están en el secreto y nada se ganaría con partirlo en mil pedazos si, por el contrario, es tan dulce guardarlo y compartirlo sólo con la persona elegida. (En Domínguez 111) ${ }^{9}$

6 Nandino cuenta, sin embargo, que Villaurrutia sintió una repulsión violenta por Barba Jacob (107), aunque Nandino no parece compartir ese sentimiento (108-109).

7 Sobre los circuitos que formaban los Contemporáneos, y los otros intelectuales homosexuales que los frecuentaban, véase Acero (37). Véanse también los ensayos de Luis Antonio de Villena y de Sergio González Rodríguez en Olea Franco y Stanton.

8 Me he ocupado del tema de la tradición homoerótica latinoamericana en "Baladas de la loca alegría" y "Los caminos del afecto", y también en El deseo, enorme cicatriz luminosa y (junto con José Quiroga) en Sexualidades en disputa. Será además el tema de un libro próximo a aparecer, Los caminos del afecto.

9 Quiroga comenta el hecho de que el amigo a quien Villaurrutia dedica el poema, Agustín J. Fink, se menciona en las memorias de Novo como dueño de un miembro viril imponente. A su vez, el tema de los marineros en el poema está glosado en las memorias de Nandino, que dice: "descubrí -junto con Roberto Rivera que también fue allá [a Los Ángeles] a hacer una investigación, pero 
La atmósfera de secretos, silencios y sospechas domina toda la poesía de Villaurrutia, sobre todo los hermosos nocturnos de Nostalgia de la muerte. Gilberto Owen comienza un poema con los versos: "La noche, que me espía por el ojo / de la cerradura del sueño" (en Domínguez 172). Escribe Jorge Cuesta en "Soñaba hallarme": "Soy el que ocultamente se retrasa / y se substrae a lo que se devora", y concluye el soneto: "Oh, muerte, ociosa para lo pasado, / sólo es tu hueco la ocasión y el nido / del defecto que soy de lo que he sido" (en Domínguez 499). Y el centro de la meditación del poema largo más ilustre del grupo, "Muerte sin fin", de José Gorostiza, es el hueco que deja, y que determina, la forma.

A la vez, hablar tanto del silencio y del secreto es insistir en la comunicación del secreto, o por lo menos en que "todos", como dice Villaurrutia, "estén en el secreto". El secreto abierto, tema de reflexión importante en algunas de las primeras obras de la teoría queer -pienso en The Novel and the Police de D. A. Miller y en Epistemology of the Closet de Eve Kosofsky Sedgwick-, inevitablemente adquiere un sentido tribal, como en la novela de Proust, o en el verso de Alfred Douglas que se hizo famoso en los juicios de Oscar Wilde, "the love that dare not speak its name" ("el amor que no se atreve a decir su nombre"). Como quiso Foucault, el insistir en la prohibición de nombrar convierte el silencio en tema de incesante conversación: lo reprimido retorna de modo obsesivo.

En el caso del poema de Pellicer con el que comencé esta discusión, es muy probable que pocos lectores hayan captado el mensaje cifrado en su momento. Por lo que me contó Monsiváis, la relación de Paz con Pellicer llegó a ser un escandalete público cuando se enteró la novia y futura mujer, Elena Garro, que gritó “¡Maricón!” delante de la casa de Pellicer. Pero no sé si eso pasó en 1931, la fecha del poema, o un tiempo después: Paz y Garro no se casaron hasta 1937. Y no sé qué pensaba Paz del poema que lo homenajeaba, con evidente referencia a su miembro viril ("cerámica fuerza"). El "adolescente tropical" desaparece después, ya lo sabemos, y se convierte en el autor de varias de las páginas más virulentamente homofóbicas de la literatura latinoamericana: ciertos pasajes de El laberinto de la soledad (y aun de Sor Fuana Inés de la Cruz o las trampas de la fe ${ }^{10}$ ).

Pero el gesto del homenaje secreto de un poema a otro, o de poemas que establecen diálogos con los de otros poetas, se hizo tradición entre los Contemporáneos (no solo entre los mexicanos sino entre los otros hispanoamericanos

más que nada a pasear- que en esa ciudad era fácil conocer marineros al por mayor" (87). Agrega recuerdos de orgías con grupos de marineros, y con curas, en una casa parroquial (89).

10 Sobre la homofobia en el estudio de Sor Juana, véase Balderston y Quiroga (75). El mismo fenómeno se produjo cuando se dieron a conocer algunos papeles personales de José Donoso, como comentamos en el mismo libro (89). 
que los frecuentaban, como Cotto, Valle y Moro). Novo escribió dos poemas hermosos sobre Villaurrutia, el poema de adolescencia "A Xavier Villaurrutia" ("escucho el ritmo de tu corazón encendido", "nos devora un ansia pecadora" [en Domínguez 365]) y otro poema de la madurez "X. V." ("tenemos la misma edad, / gustos semejantes, / opiniones diversas por sistema" [en Domínguez 414]). Jorge Cuesta escribe un "Retrato de Gilberto Owen" ("sembró en la soledad el gesto puro / que amorosa ciudad nutre y guarda" [en Domínguez 491-492]).

También de interés son las dedicatorias que hacen públicos los vínculos de amistad, complicidad o amor que hay entre los poetas. El hondureño Rafael Heliodoro Valle le dedica el poema "Ánfora sedienta" (que dará título a un poemario suyo) a Ricardo Arenales, uno de los sucesivos seudónimos de Miguel Ángel Osorio en el camino hacia el seudónimo definitivo de Porfirio Barba Jacob (de hecho, es con el nombre Ricardo Arenales que se hace famoso como homosexual en el cuento de Rafael Arévalo Martínez, "El hombre que parecía un caballo"). El soneto de Valle culmina en el sexteto:

Creo que la neblina en la tormenta arde en el ritmo puro y lo ilumina.

La noche es como un ánfora sedienta

en que fulguran gemas silenciosas...

Creo en la noche y en la neblina.

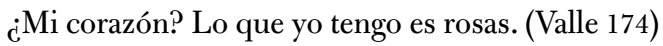

Valle también dedica poemas a Jaime Torres Bodet ("Las mariposas") y a Gabriela Mistral ("Las limonarias"). El caso de Juan Cotto, poeta salvadoreño que estuvo vinculado a los Contemporáneos, es aún más curioso: casi todos sus poemas están dedicados: "Signos", a Rubén Salazar Mallén; "Pinos", a Xavier Villaurrutia; "Higos", a Rafael Arévalo Martínez; "Girasoles", a Carlos Pellicer y, en el caso más delirante, la "Epístola a León Felipe", dedicado no al poeta español sino a Enrique Morales Pardavé.

Las circunstancias de muchos de los poemas se han perdido, aunque algunos fragmentos se pueden reconstruir a través de las dos biografías que escribió Fernando Vallejo de Porfirio Barba Jacob, la autobiografía (La estatua de sal) y algunas crónicas de Salvador Novo, la especie de autobiografía que dictó Elías Nandino en la vejez a un joven periodista (Elías Nandino, una vida no/velada), y algunos ensayos y crónicas de Carlos Monsiváis. Uno se pregunta, por ejemplo, a quién le escribe Rafael Heliodoro Valle el poema "Holocausto", un soneto que dice así: 
Eres como el ícono bizantino

del Ensueño, que al ara se convierte;

eres en los misales de la Muerte

la mayúscula roja del Destino.

Eres suntuoso vaso tan divino,

el de la letanía, el que pervierte,

el de marfil, el blanco, pero el fuerte,

donde se escancia del Amor el vino.

En ti la arcilla original se aclara

y el Espíritu Santo está poseso.

Eres el madrigal, eres el ara...

Y en tu sagrario está, de carne y hueso,

el cáliz ideal que cincelara

un taciturno lapidario, ;el Beso! (Valle 167-168)

No es que sea un poema especialmente bueno, pero el curioso cristianismo bizantino, decadente y pervertido, afirma la carne y el hueso, el "suntuoso vaso" hecho de "arcilla original", que establece vínculos extraños con la "cerámica fuerza" del poema de Pellicer y con el vaso de "Muerte sin fin" de Gorostiza.

A veces los poemas buscan el diálogo. "Amor condusse noi ad una morte" de Villaurrutia se urde explícitamente a partir de "Amor" de Novo, como han notado muchos críticos. El poema de Novo dice así:

Amar es este tímido silencio cerca de ti, sin que lo sepas, y recordar tu voz cuando te marchas y sentir el calor de tu saludo.

Amor es aguardarte como si fueras parte del ocaso, ni antes ni después, para que estemos solos entre los juegos y los cuentos sobre la tierra seca.

Amar es percibir, cuando te ausentas, tu perfume en el aire que respiro, y contemplar la estrella en que te alejas cuando cierro la puerta de la noche. (en Domínguez 413) 
El de Villaurrutia (cuyo título viene del canto V del Inferno, verso 106, el prólogo a la historia de Paolo y Francesca) es más largo, y es una especie de glosa del breve poema de Novo:

Amar es una angustia, una pregunta, una suspensa y luminosa duda; es un querer saber todo lo tuyo y a la vez un temor de al fin saberlo.

Amar es reconstruir, cuando te alejas, tus pasos, tus silencios, tus palabras, y pretender seguir tu pensamiento cuando a mi lado, al fin inmóvil, callas.

Amar es una cólera secreta, una helada diabólica soberbia.

Amar es no dormir cuando en mi lecho sueñas entre mis brazos que te ciñen, y odiar el sueño en que, bajo tu frente, acaso en otros brazos te abandonas.

Amar es escuchar sobre tu pecho hasta colmar la oreja codiciosa, el rumor de tu sangre y la marea de tu respiración acompasada.

Amar es absorber tu joven savia y juntar nuestras bocas en un cauce hasta que de la brisa de tu aliento se impregnen para siempre mis entrañas.

Amar es una envidia verde y muda, una sutil y lúcida avaricia.

Amar es provocar el dulce instante en que tu piel busca mi piel despierta; saciar a un tiempo la avidez nocturna y morir otra vez la misma muerte provisional, desgarradora, oscura. 
Amar es una sed, la de la llaga

que arde sin consumirse ni cerrarse,

y el hambre de una boca atormentada

que pide más y más y no se sacia.

Amar es una insólita lujuria

y una gula voraz, siempre desierta.

Pero amar es también cerrar los ojos,

dejar que el sueño invada nuestro cuerpo

como un río de olvido y de tinieblas,

y navegar sin rumbo, a la deriva:

porque amar es, al fin, una indolencia. (en Domínguez 138-139)

Elocuente sobre la relación entre el cuerpo y la imaginación, este poema de Villaurrutia abre la lectura de una serie de otros del grupo, como "Junto a tu cuerpo totalmente entregado al mío" de Novo, en el que también se siente, en su peso y su bulto, la figura del amado ausente. Lo más notable de la teoría amorosa esbozada aquí es que el ausente está más que el presente, cuando se cierran los ojos, cuando en el decir del poeta se debe "reconstruir" cuando está lejos.

Octavio Paz dice de Villaurrutia que fue más recatado en la expresión de sus costumbres sexuales que Novo:

La reserva de Xavier contrastaba con la jactancia de Novo. Mientras Novo hacía una suerte de ostentación de sus inclinaciones sexuales, Xavier defendía su vida privada. No creo que fuese hipocresía. No se ocultaba y era capaz de hacer frente a la condenación pública. Era discreto lo mismo en la vida real que en la literatura. (Xavier Villaurrutia 16$)^{11}$

Y en el mismo ensayo nota que Villaurrutia encabezó el pequeño comité, constituido también por Paz, Emilio Prados y Juan Gil-Albert, que recopiló la famosa antología Laurel: antología de la poesía moderna en lengua española en 1941. Vale recordar aquí, en el marco de un homenaje a Gil-Albert y sus contribuciones a la temática homoerótica en lengua española, que dicha antología tenía mucho que ver con los gustos poéticos cultivados por los Contemporáneos. Pero se pue-

11 Agrega Nandino: "Del lado de Villaurrutia creo que el tema de la muerte en sus poemas en buena medida es producto de la angustia existencial que le causaba su homosexualidad" (127). Cuenta un sueño en el que pone su mano en la rodilla de Villaurrutia mientras le habla, solo para despertarse y darse cuenta de que el amigo se ha muerto (147). 
de decir, en contra del recato afirmado por Paz, que Villaurrutia sí disfrutaba del escándalo, aunque fuera en grado menor al goce que sentía Novo: "Aragón Leiva me llama 'crítico libidinoso', calificativo que me encanta" (Villaurrutia, Cartas 57).

Villaurrutia le dice a Novo en una carta de su único viaje fuera de México, a Estados Unidos en 1935-1936: "Por fin reconoces que soy capaz de guardar secretos. El que me confías es interesantísimo" (37). Noten bien que el secreto se menciona en la carta pero no se revela: solo los amigos pueden descifrar el mensaje. Novo publica la carta (junto con muchas otras) varias décadas después de la muerte de Villaurrutia, pero no aclara a qué secretos se refieren. Sus memorias, a su vez, se confían a Carlos Monsiváis, quien hace publicar algunos fragmentos en los años setenta, poco después de la muerte de Novo, aunque no logra publicar hasta 1998 la totalidad del escandaloso libro. A su vez, César Moro le escribe a Villaurrutia poco antes de la muerte de este:

Querido Xavier, gracias por tu libro, por tu país, realidades latinoamericanas. Perdón si no supe expresar nuestra cabal admiración; tú sabes leer entre líneas. Que la vida -la admirable, la pavorosa vida- continúe desenvolviendo sus hilos; amar es, al fin, una indolencia. ¿Cómo no seguir en los sitios de peligro donde no caben ni salvación ni regreso? (Prestigio 427) $)^{12}$

El peligro también lo menciona Elías Nandino en las memorias que dictó a los 84 años a Enrique Aguilar, y que aparecieron con el título sugestivo de Elías Nandino, una vida no/velada: "a mí -de corazón- me gustaban los hombres y el cierto peligro que eso implicaba" $(117)^{13}$. Los diálogos de los amigos poetas son expresiones de ese recelo. Como dice Villaurrutia en su poema desde, y sobre, Los Ángeles: "todos están en el secreto / y nada se ganaría con partirlo en mil pedazos / si, por el contrario, es tan dulce guardarlo / y compartirlo solo con la persona elegida". El secreto es una parte esencial de la poética de este círculo de poetas y amantes. Como dice Lisa Block de Behar en Una retórica del silencio: "el discurso se repite y continúa. Algo termina pero empieza el silencio, de él depende" (244). Ese silencio incómodo se convierte, en los casos que he venido analizando, en una invitación al lector, del que todo depende.

12 Pedro Faverón comenta esta carta en Caminando sobre el abismo: vida y poesía en César Moro (62). Sobre la "Vida escandalosa de César Moro", comenta que ese poema "no tiene como tema principal el amatorio, aunque es evidente que su homosexualidad es uno de los motivos principales para el adjetivo 'escandalosa' que Moro atribuye a su vida, en oposición al orden de una vida burguesa, convencional y tibia" (73). En contraste, ver el artículo de Magdalena García Pinto, que toma su título de ese poema y afirma la centralidad de la homosexualidad para entender la poesía de Moro.

13 Después Nandino cambió de opinión sobre el trabajo de Aguilar y publicó funtando mis pasos para contar la verdad de su vida. 


\section{Obras citadas}

Acero, Rosa María. Novo ante Novo: un novísimo personaje homosexual. Madrid: Pliegos, 2003.

Aguilar, Enrique. Elías Nandino: una vida no/velada. México: Grijalbo, 1986.

Balderston, Daniel. El deseo, enorme cicatriz luminosa: ensayos sobre homosexualidades latinoamericanas. Rosario: Beatriz Viterbo, 2004.

— "Los caminos del afecto: la invención de una literatura queer en América Latina". Revista de Crítica Literaria Latinoamericana 63-64 (2006): 125-149.

- "Baladas de la loca alegría: literatura queer en Colombia". Revista Iberoamericana 225 (2008): 1059-1073.

Balderston, Daniel y José Quiroga. Sexualidades en disputa: homosexualidades, literatura y medios de comunicación en América Latina. Buenos Aires: Libros del Rojas, Universidad de Buenos Aires, 2005.

Block de Behar, Lisa. Una retórica del silencio: funciones del lector y procedimiento de la lectura literaria. México: Siglo XXI, 1984.

Carrillo Martínez, Noé. "Trizar la distancia, romper el aire". Xavier Villaurrutia et al. Y mi voz que madura. México: Conaculta, 2003. 107-117.

Cotto, Juan. Cantos de la tierra prometida. San Salvador: Consejo Nacional para la Cultura y el Arte, 1997.

Cozarinsky, Edgardo. Museo del chisme: ensayo y relatos. Buenos Aires: Emecé, 2005.

Domínguez Sosa, Blanca Estela, comp. Contemporáneos: obra poética. Barcelona: DVD Ediciones, 2001.

Elvridge-Thomas, Roxana, comp. Villaurrutia: . . y y mi voz que madura. México: Fondo Editorial Tierra Adentro, 2003.

Faverón, Pedro. Caminando sobre el abismo: vida y poesía en César Moro. Lima: Antares, Artes y Letras, 2003.

García Pinto, Magdalena. "La vida escandalosa de César Moro: autorrepresentación, exilio y homosexualidad". Sexualidad y nación. Comp. Daniel Balderston. Pittsburgh: Instituto Internacional de Literatura Iberoamericana, 2000. 283-294.

Mendiola, Víctor Manuel. Xavier Villaurrutia: la comedia de la admiración. México: Fondo de Cultura Económica, 2006.

Miller, D. A. The Novel and the Police. Berkeley: University of California Press, 1989.

Molloy, Sylvia. "Disappearing Acts: Reading Lesbian in Teresa de la Parra". ¿Entiendes? Queer Readings, Hispanic Writings. Comps. Emilie Bergmann y Paul Julian Smith. Durham: Duke University Press, 1995. 230-256.

— "Secreto a voces: traslados lésbicos en Teresa de la Parra". Poses de fin de siglo: desbordes del género en la modernidad. Buenos Aires: Eterna Cadencia, 2012. 262-287. 
Moro, César. Prestigio del amor. Comp. Ricardo Silva-Santiesteban.

Lima: Pontificia Universidad Católica del Perú, 2002.

- La tortuga ecuestre y otros poemas en español. Comp. e introducción

Américo Ferrari. Madrid: Biblioteca Nueva, 2002.

Nandino, Elías. Funtando mis pasos. México: Aldus, 2000.

Novo, Salvador. La estatua de sal. Comp. e introducción Carlos

Monsiváis. México: Consejo Nacional para la Cultura, 1998.

Olea Franco, Rafael y Anthony Stanton, comps. Los Contemporáneos en el laberinto de la crítica. México: El Colegio de México, 1994.

Oropeza, Salvador. The Contemporáneos Group: Rewriting Mexico in the

Thirties and Forties. Austin: University of Texas Press, 2005.

Paz, Octavio. El laberinto de la soledad. México: Fondo de Cultura Económica, 1950.

- Xavier Villaurrutia en persona y en obra. México: Fondo de Cultura Económica, 1978.

- La llama doble: amor y erotismo. Barcelona: Seix Barral, 1993.

Pellicer, Carlos. Poesía completa. Comps. Luis Mario Schneider y Carlos Pellicer

López. 3 vols. México: Consejo Nacional para la Cultura; Universidad

Nacional Autónoma de México; Ediciones del Equilibrista, 1996.

Quiroga, José. Tropics of Desire: Interventions from Queer Latino

America. Nueva York: New York University Press, 2000.

Sedgwick, Eve Kosofsky. Epistemology of the Closet. Berkeley:

University of California Press, 1990.

Valle, Rafael Heliodoro. Ánfora sedienta: poemas. México: Manuel León Sánchez, 1922.

Vallejo, Fernando. Barba facob, el mensajero. México: Séptimo Círculo, 1984.

- El mensajero: una biografía de Porfirio Barba facob. 1991. Bogotá: Alfaguara, 2003.

Villaurrutia, Xavier. Cartas de Villaurrutia a Novo (1935-1936). México:

Instituto Nacional de Bellas Artes, Departamento de Literatura, 1966.

- Antología. Comp. e introducción Octavio Paz. México:

Fondo de Cultura Económica, 1980.

Villaurrutia, Xavier, Emilio Prados, Juan Gil-Albert y Octavio Paz, comps. Laurel: antología de la poesía moderna en lengua española. México: Séneca, 1941. 